\title{
Practice, refractive error, and feedback as factors influencing peripheral motion thresholds*
}

\author{
CHRIS A. JOHNSON and HERSCHEL W. LEIBOWITZ \\ The Pennsylvania State University, University Park, Pennsylvania 16802
}

\begin{abstract}
Motion thresholds were determined in the fovea and in the horizontal peripheral meridian under conditions of practice, correction of refractive error, and feedback. While foveal determinations did not change significantly, peripheral motion thresholds were lowered for all conditions. Both practice and practice with feedback produced significantly better motion discrimination, these effects showing a longevity of several months. However, the largest improvement resulted from correction of peripheral refractive error, which also reduced individual differences. This suggests that peripheral sensitivity to movement is ordinarily limited primarily by dioptric rather than neural factors. Implications for perceptual learning and peripheral vision research are discussed.
\end{abstract}

The ability to discriminate visual stimuli declines progressively with increase in the angle of eccentricity. Since peripheral stimulation generally provides important cues for directing eye movements for foveal fixation, off-axis detection of stimuli is a major function of the peripheral visual fields (LeGrand, 1967). Movement is a particularly effective peripheral stimulus, since it is degraded to a much lesser extent than other visual functions in the periphery (for a review of peripheral motion studies, see Graham, 1965, or LeGrand, 1967).

The purpose of the present study was to investigate several factors affecting detection of movement in the periphery and to determine the extent to which these factors limit peripheral performance. In the periphery, both retinal resolution and the quality of the retinal image are degraded, so that it is not possible to attribute impaired peripheral performance to a single source. Since very large refractive errors have been reported in the periphery (Ferree \& Rand, 1933), it was decided to investigate the effects of correcting peripheral refractive error on movement thresholds (Experiment II). In view of the general observations that peripheral discriminations improve with practice (Low, 1952; Saugstad \& Lie, 1964), the effects of practice (Experiment I), feedback (Experiment III), and the longevity of practice and feedback effects (Experiment IV) on peripheral movement thresholds were also determined.

\section{EXPERIMENT I}

Method

The effect of practice on movement thresholds was determined at nine stimulus locations in the horizontal meridian,

Supported by Grant MH08061 from the National Institute of Mental Health and Grant GY-9866 from the National Science Foundation. Aspects of the data were presented to The Japanese Psychological Association (1972), The Psychonomic Society (1972), and the Eastern Psychological Association (1973). The authors are indebted to Ed Isabelle. Takeo Iida, Ken Shiina, and Judy Meighan for help and assistance, to Jay Enoch for advice and encouragement, and to Larry $G$. Kerr for his valuable comments on the manuscript. from 0 to $80 \mathrm{deg}$ of eccentricity in 10 -deg intervals. Four psychology students, experienced in visual psychophysics, served as Ss. The $S$ was seated facing a perimeter $154.0 \mathrm{~cm}$ in diam, with a $1.27-\mathrm{cm}$ slit cut horizontally along its surface at eye level. The interior of the perimeter was covered with black paper (reflectance $1.8 \%$ ) and uniformly illuminated by two horizontal panels of incandescent lights $(6.91 \mathrm{fc})$.

Movement of the stimulus was accomplished by a 20.3-cm-diam cylinder covered with black paper (reflectance $1.8 \%)$ and mounted with its long axis horizontal behind the slit opening. A $1.27-\mathrm{cm}$-wide band of white plastic tape (reflectance $65.6 \%$ ) was wrapped in a single helix around the cylinder. Rotating the cylinder behind the slit produced horizontal movement of an approximately square-shaped white test stimulus subtending $0.95 \mathrm{deg}$ of visual angle. Direction and velocity of the moving test stimulus were controlled by a 10-ratio gear reducer connected to a synchronous dc motor and controller with a micrometer dial. Periodic calibration of the control motor-gear reducer combination was accomplished with a Strobotac (Model 1531-A). The cylinder, motor, and gear reducer were mounted on a bracket which was moved along a track on the outside of the perimeter. A constant stimulus duration of $1.0 \mathrm{sec}$ was provided by a Hunter timer. Noise and vibration produced by the motor were masked by an electric fan.

Movement thresholds at the nine eccentricities were determined for the temporal visual field of the dominant (right) eye at an observation distance of $77 \mathrm{~cm} .1$ The S's head was positioned in a head- and chinrest, and instruction and practice were given on a blind-spot fixation method similar to that described in Teuber, Battersby, and Bender (1960). This consisted of imaging a $1.27 \times 5.08 \mathrm{~cm}(0.95 \times 3.80 \mathrm{deg})$ white stimulus within their blind spot. This fixation stimulus (reflectance $65.5 \%$ ) was centered at 15 -deg eccentricity on the perimeter. Eye movements of greater than about 1 deg became apparent immediately to the $S$ by awareness of the fixation stimulus.

Each session consisted of threshold determinations at each of the nine eccentricities, presented in successive order from the fovea to $80 \mathrm{deg}$. After each trial, Ss reported whether the stimulus had moved to the left, to the right, or was stationary. Trials during which eye movements occurred were disregarded. An interleaved double staircase (Cornsweet, 1962) with variabie step size was used to determine the movement thresholds, and a $50 \%$ correct criterion was selected as the threshold measure. The Ss were tested for four sessions on consecutive days, each session lasting 1.0 to $1.5 \mathrm{~h}$.

\section{Results}

Figure 1 presents movement thresholds obtained for 


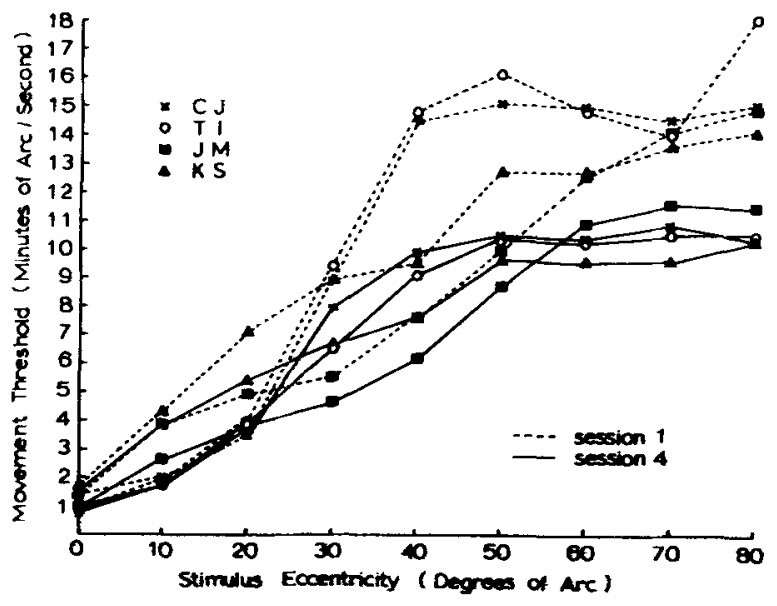

Fig. 1. Motion thresholds during the first and last practice sessions for each $\mathbf{S}$.

each S during the first and fourth practice sessions as a function of stimulus eccentricity. In all cases, the thresholds for the fourth session are lower than for the initial session. Movement thresholds appear to increase to about $50 \mathrm{deg}$ of eccentricity and remain fairly constant beyond that point.

An analysis of variance with repeated measures revealed significant differences for stimulus eccentricity $[F(8,24)=14.78, p<.001]$, sessions (practice) $[F(3,9)$ $=77.61, \mathrm{p}<.0011$, and the interaction between stimulus eccentricity and sessions $[F(24,72)=5.64$, $\mathrm{p}<.001]$. Duncan's least significant difference test revealed significant differences $(p<.01)$ between all sessions at each eccentricity beyond $20 \mathrm{deg}$, except between Sessions 3 and 4.

These results indicate that practice seems to have lit tle effect on movement thresholds in the fovea and near periphery, but greatly improves detection of movement beyond $20 \mathrm{deg}$ of eccentricity. The major effect of practice was realized by the third session, beyond which little improvement occurs.

\section{Discussion}

In confirmation of previous investigations, peripheral movement detection improves with practice. Furthermore, the present results imply the superiority of peripheral movement detection when compared with other visual functions in the periphery. Movement thresholds at $80 \mathrm{deg}$ of eccentricity are only 10 to 15 times greater than at the fovea, while acuity is degraded by a factor of 200 or more over this interval (LeGrand, 1967). Not only is peripheral motion detection relatively better than acuity to begin with, but the amount of practice needed for optimal performance, 3 sessions, is apparently less than that needed for acuity ( 25 sessions according to Low, 1946, and 15 sessions as reported by Saugstad and Lie, 1964). The theoretical basis for improved peripheral discrimination with practice is not clear. Low (1946) has suggested that it may be due to learning to use a previously unpracticed sensory area, while Saugstad and Lie (1964) attribute the improvement to learning to shift the maximum momentary level of attention from central to peripheral parts of the visual field. In either case, it is reasonably clear that some form of perceptual learning occurs with practice (see Gibson, 1969).

\section{EXPERIMENT II}

In view of the large refractive errors reported in the periphery (Ferree \& Rand, 1933), this experiment was designed to determine their effect on movement thresholds. A preliminary report of this aspect of the study has been published previously (Leibowitz, Johnson, \& Isabelle, 1972). The present results include data for an additional $S$.

\section{Method}

The apparatus, procedure, and $S s$ were the same as in Experiment I. Prior to the sessions in Experiment Il, the spherical and astigmatic refractive errors were determined by an experienced optometrist for each $S$ at the nine stimulus eccentricities. 2 This procedure involved placing a retinoscope at the stimulus locations and determining the appropriate correction by static retinoscopy while $S$ fixated as during the experimental sessions. A lens holder, $1.27 \mathrm{~cm}$ from the S's eye, positioned the appropriate ophthalmic trial lenses, correcting spherical and astigmatic refractive errors so as to be properly aligned with the stimulus at each of the various eccentricities. Four sessions, two with and two without correction of refractive error, were held on successive days. The order of presentation of with- and without-correction sessions was counterbalanced among Ss.

\section{Results}

The results of the peripheral refractions are given in Table 1. These data are in agreement with those of Ferree and Rand (1933), who reported large peripheral refractive errors between 0 and 60 deg of eccentricity. In addition, individual differences in the amount and direction of refractive error, i.e., towards myopia or hyperopia, are apparent in the present study, also in confirmation of Ferree and Rand. ${ }^{3}$

Movement thresholds as a function of eccentricity, with and without correction of refractive error, are presented for individual Ss in Fig. 2. The data from both sessions for each condition were similar and therefore were combined. Except for S J.M., there appears to be good correspondence between the values of movement thresholds without correction and the amount of peripheral refractive error. ${ }^{4}$ Most importantly, it can be observed that movement thresholds were lowered by nearly one-half after refractive error was corrected, and that the individual differences were markedly reduced.

An analysis of variance with repeated measures showed significant differences for stimulus eccentricity $[F(8,24)=109.605, p<.001]$, correction vs no correction of refractive error $[F(1,3)=52.128$, $\mathrm{p}<.01]$, and their interaction $[\mathrm{F}(8,24)=16.978$, $\mathrm{p}<.001]$. Duncan's least significant difference test 
revealed significant differences $(p<.01)$ between movement thresholds for with and without correction of refractive error at every location except for the fovea, indicating that the improvement after correcting refractive error occurs mainly in the periphery.

\section{Discussion}

It is not surprising that a marked improvement in peripheral motion detection occurs after correction of the refractive errors observed in the periphery, since such large refractive errors produce considerable blurring of the retinal image. Refractive error might also explain why movement detection is superior to other functions in the periphery, assuming that the quality of the retinal image is even more critical for contour-related phenomena such as acuity. Most importantly, the present results indicate that dioptric variables are an important limiting factor in peripheral discriminations.

Table 1

Spherical and Cylindrical Correction, in Diopters, Required for Individual Ss as Determined by Static Retinoscopy

\begin{tabular}{|c|c|c|c|c|}
\hline \multirow[b]{2}{*}{$\mathbf{s}$} & \multirow{2}{*}{$\begin{array}{l}\text { Stimulus } \\
\text { Eccentri- } \\
\text { city (Deg) }\end{array}$} & \multicolumn{2}{|c|}{ Correction } & \multirow{2}{*}{$\begin{array}{c}\text { Cylinder } \\
\text { Axis } \\
\text { (Deg) }\end{array}$} \\
\hline & & Spherical & Cylindrical & \\
\hline K.S. & $\begin{array}{r}0 \\
10 \\
20 \\
30 \\
40 \\
50 \\
60 \\
70 \\
80\end{array}$ & $\begin{array}{l}-2.25 \\
-2.25 \\
-2.00 \\
-1.50 \\
-0.50 \\
+2.25 \\
+3.50 \\
+4.00 \\
+5.50\end{array}$ & $\begin{array}{l}-0.50 \\
-0.50 \\
-0.50 \\
-0.50 \\
-0.50 \\
-1.00 \\
-1.00 \\
-1.00 \\
-1.00\end{array}$ & $\begin{array}{l}180 \\
180 \\
180 \\
180 \\
170 \\
150 \\
150 \\
150 \\
145\end{array}$ \\
\hline T.I. & $\begin{array}{r}0 \\
10 \\
20 \\
30 \\
40 \\
50 \\
60 \\
70 \\
80\end{array}$ & $\begin{array}{l}+1.00 \\
+1.00 \\
+1.00 \\
+1.00 \\
+1.00 \\
+0.87 \\
+0.87 \\
+0.87 \\
+0.87\end{array}$ & $\begin{array}{l}-1.25 \\
-1.25 \\
-1.50 \\
-1.50 \\
-1.75 \\
-1.75 \\
-2.00 \\
-2.00 \\
-2.25\end{array}$ & $\begin{array}{l}90 \\
90 \\
85 \\
80 \\
80 \\
75 \\
70 \\
70 \\
65\end{array}$ \\
\hline C.J. & $\begin{array}{r}0 \\
10 \\
20 \\
30 \\
40 \\
50 \\
60 \\
70 \\
80\end{array}$ & $\begin{array}{l}+0.87 \\
+0.87 \\
+0.87 \\
+0.87 \\
+0.87 \\
+3.25 \\
+7.50 \\
+7.50 \\
+8.00\end{array}$ & $\begin{array}{l}-0.25 \\
-0.25 \\
-0.50 \\
-0.50 \\
-0.75 \\
-0.75 \\
-0.75 \\
-0.75 \\
-1.00\end{array}$ & $\begin{array}{l}90 \\
90 \\
85 \\
80 \\
80 \\
75 \\
70 \\
70 \\
65\end{array}$ \\
\hline J.M. & $\begin{array}{r}0 \\
10 \\
20 \\
30 \\
40 \\
50 \\
60 \\
70 \\
80\end{array}$ & $\begin{array}{l}+1.00 \\
+1.00 \\
+1.00 \\
+0.50 \\
+0.50 \\
+0.25 \\
+0.25 \\
+0.12 \\
+0.12\end{array}$ & $\begin{array}{r}-0.25 \\
-0.25 \\
-0.25 \\
0.00 \\
0.00 \\
0.00 \\
0.00 \\
-0.50 \\
0.75\end{array}$ & $\begin{array}{l}180 \\
180 \\
180 \\
180 \\
180 \\
180 \\
180 \\
135 \\
135\end{array}$ \\
\hline
\end{tabular}

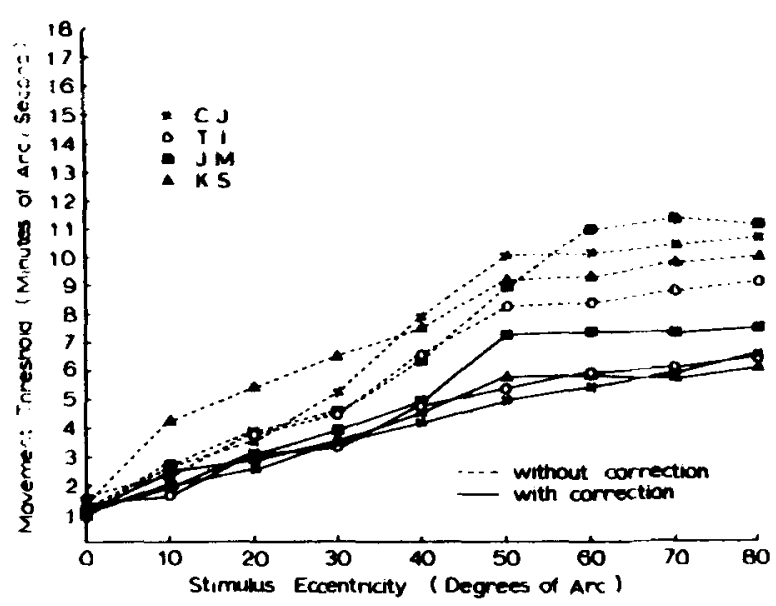

Fig. 2. Motion thresholds for each $S$ with and without correction of refractive error at each eccentricity.

\section{EXPERIMENT III}

Experiment III investigated whether providing Ss with knowledge of their performance (feedback) would improve performance beyond the effect of practice and correction of refractive error. The apparatus, procedure, and Ss were the same as those in the previous experiments. However, in this experiment, Ss werc informed what the correct response was after each trial. Eight sessions, four with and four without correction of refractive error were conducted on successive days. The two session types were presented in alternating order, with the initial session type counterbalanced among Ss.

\section{Results}

Individual movement thresholds as a function of eccentricity for all of the feedback sessions, with and without refractive error correction, are presented in Fig. 3. In almost all cases, movement thresholds obtained with correction of refractive error are lower than those without correction for all sessions. However, without correction, feedback leads to improvement over sessions, whereas with correction there is no appreciable change in thresholds as a function of feedback.

An analysis of variance with repeated measures revealed significant differences for sessions $[F(3,9)=$ 13.83, $p<.005]$, correction vs no correction $[F(1,3)=$ 147.57, $p<.005]$, and stimulus eccentricity $[F(8,24)=$ $100.72, \mathrm{p}<.0011$. All interactions between these factors were also significant at the $p<.01$ level or better. Duncan's least significant difference test showed significant differences $(p<.01)$ between sessions without correction of refractive error al eccentricities of $30 \mathrm{deg}$ and beyond, except for several eccentricities which showed no significant differences between Sessions 3 and 4 . No differences were found between the with-refractive-error-correction sessions at any eccentricity. Comparing the fourth sessions of with and 

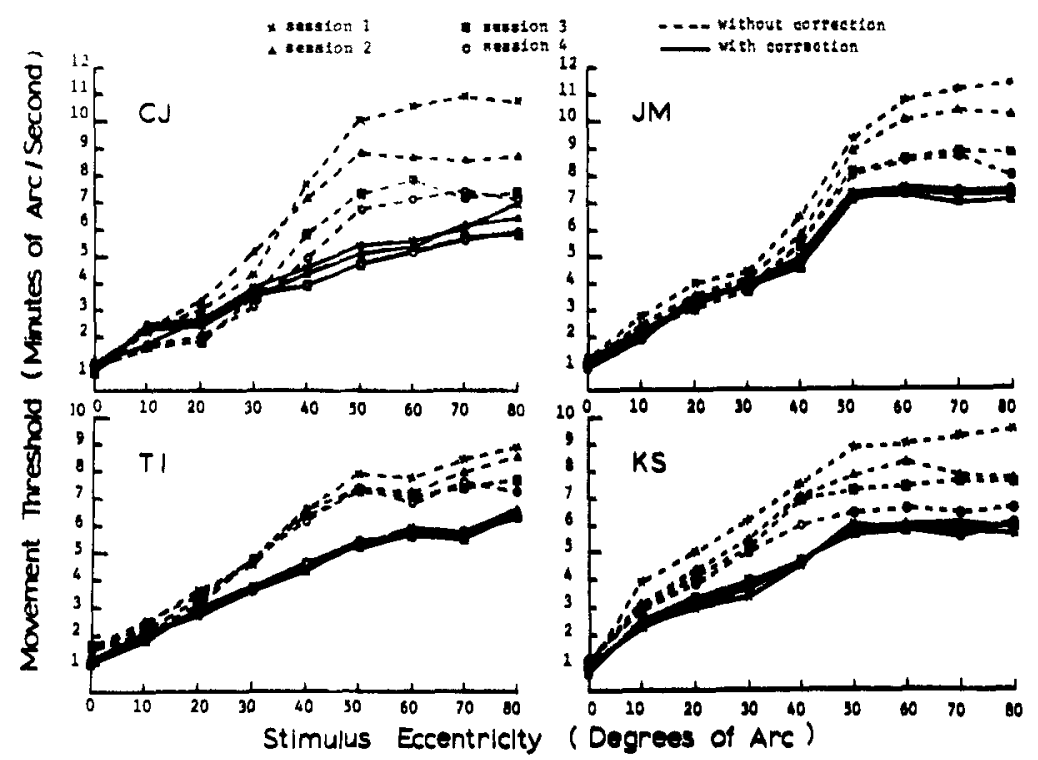

Fig. 3. Motion thresholds of individual Ss during feedback sessions with and without correction of refractive emor. without correction, significant differences $(p<.01)$ were found for $30 \mathrm{deg}$ and beyond.

\section{Discussion}

Feedback improves movement detection in the periphery if refractive error is present, but has no effect when refractive error is properly corrected. Even after improvement from feedback, correction of refractive error still produces significantly lower movement thresholds in the periphery than without correction.

The fact that feedback improved peripheral movement detection only when refractive error was not corrected suggests that feedback served to improve the interpretation of a degraded image. The $\mathrm{S}$ may have been able to extract relevant cues from a blurred image through the correction of response function of feedback (Gibson, 1969), which assisted movement detection. Since correcting refractive error improves image quality, feedback made no difference. Thus, while a good-quality image produces the lowest movement thresholds, feedback helps in the interpretation of a poor-quality image.

\section{EXPERIMENT IV}

Experiment IV was a follow-up to the first three experiments. Three of the four original Ss (J.M., C.J., and K.S.) were tested at 1- and 3-month intervals after the final feedback session. The same apparatus and procedure used in Experiment I were employed here. All sessions were conducted without correction of refractive error.

Figure 4 presents the mean thresholds for the three Ss for the 1- and 3-month follow-up sessions, with the mean thresholds from the initial, after-practice, and after-practice-plus-feedback sessions presented for comparison. No statistical comparisons were made, because the practice and feedback effects are not separable in this experiment. It can readily be seen that after 1 month, movement thresholds are somewhat higher than those after practice plus feedback, but are generally lower than those obtained after practice alone. After 3 months, the thresholds obtained are similar to those obtained after practice alone.

\section{Discussion}

The results of Experiment IV indicate that the improvement in motion discrimination with practice and feedback is not a short-term effect. Considerable savings were observed for up to 3 months following practice and feedback sessions. The similarity of the thresholds obtained after 3 months to those obtained after practice suggests that practice effects might be longer lasting than feedback effects. This introduces the possibility that

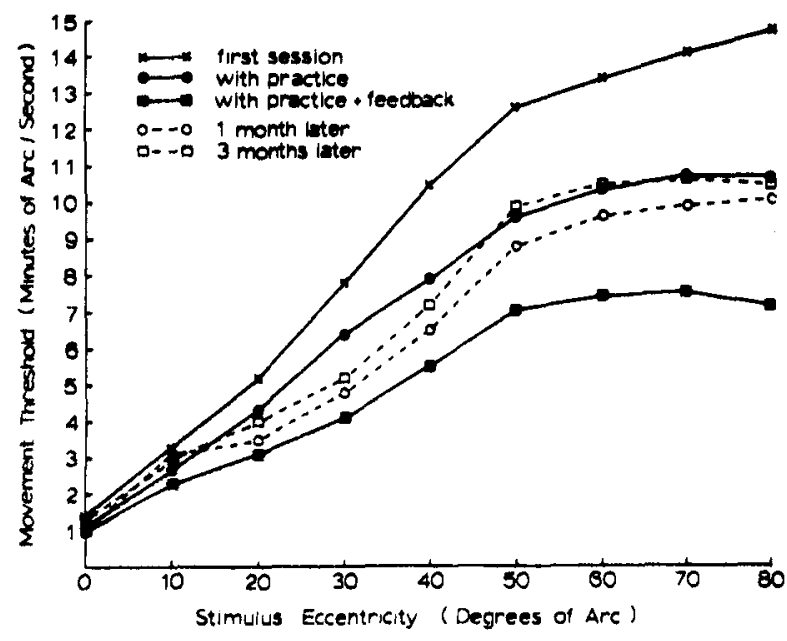

Fig. 4. Mean motion thresholds for three Ss after practice, feedback, and 1 and 3 months after Experiment III. 
practice and feedback effects may be the result of two separate types of perceptual learning. However, further research is necessary on this problem, as it is not possible unequivocally to separate practice from feedback effects in the present study.

\section{GENERAL DISCUSSION}

While discrimination in the peripheral visual fields is degraded with respect to the fovea, sensitivity to movement declines to a much smaller degree than does resolution. It has generally been assumed that the "coarse" resolution of the peripheral retina and neural properties such as larger receptive fields in the periphery were responsible for its poor performance. However, the results of the present study imply that the quality of the retinal image is a major factor in peripheral performance. Dioptric variables were shown to be a limiting factor in detection of movement in the periphery and would most likely also influence other visual measures. This finding suggests that peripheral retinal image quality is an important factor for consideration in visual search and other tasks concerned with peripheral visual performance. It should also be pointed out that investigation of neurological properties of the peripheral visual fields should include correction for peripheral refractive error in order to eliminate the influence of dioptric variables (Enoch, Sunga, \& Bachman, 1970; Fankhauser \& Enoch, 1962).

Although correction of refractive error produces the most pronounced effects, practice and feedback also improve movement detection for the uncorrected periphery. It is heuristic to assume that practice and feedback effects might possibly be the result of two separate types of perceptual learning. With practice, Ss seem to learn to effectively use the periphery or shift attention to the periphery momentarily. This results in an enhanced awareness of peripheral stimulation in general. Improvement with feedback might occur as a result of the S's learning to extract relevant cues from a blurred image. An alternative possibility is that Ss learn to partially "correct" their peripheral spherical error through appropriate accommodation, since it has been shown that a variety of stimuli, even nonvisual ones, can serve as cues for training accommodative responses (Cornsweet \& Crane, 1973). The 1- and 3-month follow-up experiment seems to suggest the possibility of two separate types of perceptual learning.

Although the practice and feedback effects are important, the major finding of this study is the vast improvement in detection of movement in the periphery after correcting refractive error. There are many aspects of peripheral functioning and related phenomena which should be reevaluated in the light of these results, with due consideration to the dioptric characteristics of the peripheral visual fields.

\section{REFERENCES}

Cornsweet. T. N. The staircase method in psychophysics. American Journal of Psychology, 1962, 75, 485-491.

Cornsweet, T. N., \& Crane, H. D. Training the visual accommodation sy stem. Vision Research, 1973, 13, 713-715.

Enoch, J. J., Sunga, R., \& Bachman. E. A static perimetric technique believed to test receptive field properties: I. Extension of the Westheimer experiments on spatial interaction. American Joumal of Ophthalmology, 1970, 69, 113-126.

Fankhauser, F.. \& Enoch, J. M. The effects of blur on perimetric thresholds. Archives of Ophthalmology, 1062, 68, 240-251.

Ferree, C. E., \& R and, G. Interpretation of refractive conditions in the peripheral field of vision. Archives of Ophthalmology, $1933,9,025-938$

Gibson, E. J. Principles of perceptual learning and development. New York: Appleton-Century-Crofts, 1969. Pp. 163-101.

Graham, C. H. Perception of movement. In C. H. Graham (Ed.), Vision and visual perception. New York: Wiley, 1065.

LeGrand, Y. Form and space vision. (Rev, ed.) (Trans. M. Millodot and G. G. Heath.) Blooming ton: Indiana University Press, 1067. Pp. 178-102.

Leibowitz, $H$. W. The relation between the rate threshold for the perception of movement and luminance for various durations of exposure. Journal of Experimental Psychology, 1855, 49, 200-214.

Leibowitz, H. W., Johnson, C. A., \& Isabelle, E. Peripheral motion detection and refractive error. Science, 1072, 177 , 1207-1208.

Low, $\mathrm{F}$. Some characteristics of peripheral visual performance. American Journal of Physiology, 1946, 146, 573-584.

Saugstad, P., \& Lie, I. Training of peripheral visual acuity. Scandinavian Joumal of Psychology, 1964, 5, 218-224.

Teuber, H. L., Battersby, W. S., \& Bender, M. B. Visual field defects after penetrating missile sounds of the brain. Cambridge: Harvard University Press, 1960. Pp. 9-10.

\section{NOTES}

1. No correction was made for the change in effective pupil size with oblique viewing, since the luminance level employed was assumed to be on the flat portion of the motion-luminance function (Leibowitz, 1055). This was confirmed by testing at both 4.53 and $45.3 \mathrm{fL}$, both with and without correction at 60 , 70 , and $80 \mathrm{deg}$. No differences were observed as a function of luminance.

2. The authors are indebted to G. B. Stein for his skill and patience in carrying out these tedious determinations.

3. A discussion of some aspects of peripheral refraction is contained in the technical note, "Peripheral Dioptrics of the Eye," by Lamont and Millodot and the reply by the authors, Science, 1873, 182, 86-87.

4. No correction was made for the angular magnification produced by the ophthalmic trial lenses. For two of the Ss, the magnification of the stimulus became greater with correction of peripheral refractive error, whereas it diminished with correction for the other two $S s$. Since the results for all four $S s$ were similar, it is unlikely that angular magnification could have accounted for the present findings.

(Received for publication August 13, 1973; revision received October $12,1973$. ) 